\title{
Brief history of surgical timing: surgery for ruptured intracranial aneurysms
}

\author{
Sherman C. Stein, M.D. \\ Department of Neurosurgery, Hospital of the University of Pennsylvania, Philadelphia, Pennsylvania
}

\begin{abstract}
The neurosurgical profession has taken a circuitous route to attain its current knowledge about timing for aneurysm surgery. While addressing the timing issue, neurosurgeons were beset by many pressures simultaneously. They were forced to justify not only optimal surgical techniques but the need for surgery at all in the treatment of ruptured aneurysms. The beliefs of surgeons with strong personalities, in addition to intuitive guesses, often served to guide surgery in the absence of scientific evidence. That any progress could be made against a background of desperately ill patients and frustrating early results is remarkable. The author briefly outlines the controversies and misdirection that accompanied this progress toward understanding surgical timing in the treatment of ruptured aneurysms.
\end{abstract}

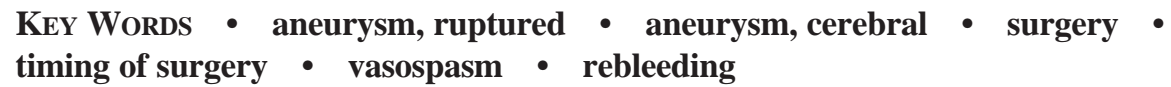

\section{THE FIRST ANEURYSM OPERATIONS}

"People have not been content to see events as unconnected and inexplicable." Stephen Hawking, A Brief History of Time

The surgical management of ruptured aneurysms has been controversial since it was first introduced. In the late 1800 s and early 1900s, scattered cases were reported in which a large intracranial aneurysm was accidentally encountered during a craniotomy for suspected brain tumor. A carotid artery ligation in the neck worked well for Horsley in 1885 , whose patient was said to be faring well 5 years later, when reported by Keen. ${ }^{31}$ Other early cases were less successful, as carotid ligations for accidentallyexposed aneurysms were often followed by cerebral infarction. ${ }^{36,57}$ The first planned ligation of a carotid artery for the treatment of a nontraumatic, saccular aneurysm was performed in $1928 .^{54}$

In 1929, Albright $^{1}$ predicted that intracranial aneurysm ligation would be curative, but Ayer ${ }^{4}$ doubted that this or any intracranial surgery would succeed: "Can surgery offer anything?" the latter despaired. "The possibility of clipping off a small berry aneurysm on one of the communicating branches might be considered, but it would be a most formidable procedure and exceedingly dangerous and, the writer feels, impracticable." Dott ${ }^{14}$ performed the first planned intracranial aneurysm operation in 1931, wrapping an aneurysm that had bled three times. The following year, Olivecrona exposed a posterior fossa aneu-

Abbreviation used in this paper: ICA = internal carotid artery. rysm, mistaking it for a tumor, and he ligated it intracranially; the patient, according to Norlén, ${ }^{44}$ made a good recovery. During the mid-1930s, Tönnis, ${ }^{61} \mathrm{McC}$ Connell, ${ }^{37}$ and others $^{58}$ wrapped and packed aneurysms of the circle of Willis, but varying degrees of success were demonstrated.

In 1937, Dandy ${ }^{7}$ first used an intracranial clip to occlude an aneurysm and, despite initial pessimism, ${ }^{10}$ reported several more intracranial procedures in $1944 .{ }^{8}$ In a presentation delivered by German ${ }^{21}$ to the Harvey Cushing Society, he and several other surgeons reported having excised aneurysms. During the 1940 s, Dott ${ }^{13}$ pioneered several intracranial procedures, including temporary clip occlusion and proximal intracranial vessel ligation. By the mid-1950s, Falconer, ${ }^{18,19}$ Hamby, ${ }^{23}$ Norlén, ${ }^{44,46,47}$ and Sjöquist ${ }^{55}$ had extended the practice of intracranial clipping and ligature to aneurysms on branches of the ICA, a feat which Dandy ${ }^{9}$ himself had considered "hopeless." The first large series of patients in whom intracranial occlusion was performed was reported by Norlén and Olivecrona ${ }^{47}$ in 1953. Of the 100 patients who underwent surgery after a 3-week "free interval quiescent period," mortality was a mere $3 \%$.

\section{JUSTIFYING SURGERY FOR RUPTURED ANEURYSMS}

In the formative years of aneurysm surgery, there was scant evidence on which to base surgery-related decisions. Neurosurgeons often had to defend their surgery-related recommendations against those who advocated well-intentioned medical therapies or even those who discussed 
the natural history of the disease. For example, in 1951 Denny-Brown ${ }^{12}$ doubted the effectiveness of aneurysm surgery, and Slosberg ${ }^{56}$ had advocated lowering blood pressure as a surgical alternative since 1956. Unfortunately, few surgical teams could equal the results of Norlén and Olivecrona, and throughout the late 1940s and into the 1950s, surgeons were reluctant to report their disappointing results. ${ }^{15,33}$ In a cooperative study of Intracranial Aneurysms and Subarachnoid Hemorrhage, the authors found reports of 518 patients who had undergone intracranial procedures before $1956 .{ }^{53}$ The average mortality rate was $21 \%(28.7 \%$ of those in whom the aneurysm had been directly attacked), but in several small series mortalities rates as high as $86 \%$ were reported..$^{53}$ Most short-term comparisons of surgery- and nonsurgery-related results failed to show any advantage for the former; $5,11,51$ the authors who did report more favorable surgery-related outcomes were often criticized for including mainly the sickest patients in the nonsurgical group. McKissock and associates $^{38,39}$ took pains to compare surgically treated aneurysm patients with control patients who were well enough to be considered for surgery. They reported that, in the short term, results of intracranial aneurysm operations were no better than medical management. In his 1963 textbook of neurology, Merritt ${ }^{41}$ recommended surgery only to evacuate large associated hematomas. Alvord and Thorn, ${ }^{3}$ who analyzed the literature on the surgical treatment of aneurysms in 1977, concluded: "In fact, when these two major determinants of patient's prognosis [clinical grade and time since bleed] were considered together, no great difference in the number of survivors (the inverse of mortality) could be detected in previously reported series of cases regardless of the method of treatment, site or number of aneurysms, or any other factor which could then be analyzed."

Surgery-related decisions were further complicated by the question of timing: how soon after aneurysmal rupture should clipping be attempted? On the one hand, surgeons were motivated by anxiety to prevent hemorrhages, which were often fatal. Pool ${ }^{49}$ went so far as to organize an "aneurysm team" to facilitate angiography and surgery as soon after hospital admission as possible. Not even Norlén and Olivecrona, ${ }^{47}$ however, achieved good results with early surgery; the mortality rate in the 15 patients in whom they operated within 3 weeks of hemorrhage was $53 \%$. In 1955, Magladery ${ }^{35}$ reported a mortality rate of $65 \%$ in patients who underwent early surgery. Results were especially disappointing in poor-grade patients; Dott $^{13}$ abandoned early surgery in them by 1955 . Again, although few authors published series on early aneurysm surgery, there were numerous anecdotal reports that, intraoperatively, the brain was usually swollen, red, and "angry." ${ }^{15}$ Neuroanesthesia was rudimentary, retraction was overly vigorous, and instruments were inadequate. The quality of visualization was poor. Even smooth-running operations could be followed by catastrophic strokes. Because early postoperative results were better after carotid artery ligation had been performed, a number of neurosurgical pioneers, such as Jefferson and Poppen, preferred it to intracranial procedures. ${ }^{15}$ Because the complication rate was forbiddingly high, ICA ligation was gradually replaced by common carotid artery ligation. By 1960, McKissock and associates, ${ }^{40}$ in a controlled trial for ruptured ICA-posterior communicating artery aneurysms, judged that short-term results of ligation were superior to bedrest in better-grade patients. For many years, authorities continued recommending carotid artery ligation in cases of certain aneurysms.

\section{ESTABLISHING SURGICAL TREATMENT}

In 1962 Tappura $^{60}$ demonstrated that medical treatment for ruptured aneurysms, which consisted of little more than bedrest, was not very effective. Of those who survived their initial hemorrhage in his series, $55 \%$ suffered rebleed and $75 \%$ of these patients died. In 1962, Norlén ${ }^{45}$ reported only three deaths of 134 patients in whom the aneurysm stalk was ligated. Nevertheless, controversy persisted beyond the late 1960s, when the results of the first cooperative study were widely published. The elements of the cooperative study of Intracranial Aneurysms and Subarachnoid Hemorrhage were reported in several articles in the Journal of Neurosurgery and were assembled into a single volume in 1969. Although a handful of patients were followed beyond 3 years, the cooperative study design did not require a follow-up period longer than 6 months. According to the study's designers, a 6-month follow-up period "appeared to encompass nearly all surgical deaths, most deaths from the initial hemorrhage, and deaths from rebleeding. ${ }^{53}$ " They discovered that the risk of rebleeding over the first few postoperative months was higher than previously recognized, and, although the risk of a second hemorrhage diminished thereafter, $11 \%$ of the cases in which rebleeding occurred were recorded more than 1 year postoperatively. There was a clear advantage of surgery over bedrest (Table 1). Although the authors of the cooperative study warned against comparing results in the nonrandomized groups, this is exactly what was done by many in the medical community.

There were a total of 800 cases of carotid artery ligation reviewed by the cooperative study. Although the shortterm mortality rate was lower than that associated with intracranial surgery (Table 1), the extracranial ligation procedure was found to be effective only for aneurysms of the ICA itself and was associated with a $30 \%$ stroke rate. ${ }^{42}$ Because authors of subsequent studies underscored the lack of long-term protection against rebleeding associated with carotid artery ligation, this procedure was eventual replaced by intracranial procedures. ${ }^{25,62}$

As technical advances led to better surgery-related results and long-term follow-up studies revealed that the risk of rebleeding of unclipped aneurysms continued for years and was much higher than previously believed, aneurysm clipping became increasingly more favored. In

TABLE 1

Six-month treatment-related mortality in aneurysm surgery*

\begin{tabular}{lccc}
\hline \hline Treatment & $\begin{array}{c}\text { No. of } \\
\text { Patients }\end{array}$ & $\begin{array}{c}\text { No. of } \\
\text { Deaths }\end{array}$ & $\begin{array}{c}\text { 6-mo Mortality } \\
\text { Rate (\%) }\end{array}$ \\
\hline intracranial surgery & 572 & 186 & 32.5 \\
carotid artery ligation & 382 & 79 & 20.7 \\
bedrest & 324 & 162 & 50.0 \\
\hline
\end{tabular}

* Derived from the cooperative study published by Locksley, 1969. 
long-term follow-up studies reported by Pakarinen ${ }^{48}$ and Alvord and associates, ${ }^{2,3}$ the authors showed that the risk of rebleeding continues for many years in patients in whom clipping is not performed. In fact, when Winn and associates $^{63}$ followed McKissock's medically treated patients for 10 years, they discovered that he had considerably underestimated the risk of the natural history of the disease. Since the mid-1950s surgery-related advan-ces have been dramatic, although results have varied considerably among centers. In 1956, Botterell, et al., ${ }^{6}$ introduced the concept of clinical grading to guide management of ruptured aneurysms. Hunt and Hess ${ }^{24}$ demonstrated that a patient's clinical grade influences outcome of medical and surgical treatment. In 1968, they introduced an improved grading system, which allowed rational characterization of patient populations. ${ }^{24}$ They were able to show that early surgery in good-grade patients was highly successful. Several technical advances were directly beneficial; others, such as operative hypothermia and hypotension, stimulated exploration of improved surgical techniques. ${ }^{15}$ Although first used by Kurze $^{32}$ in 1957, the operating microscope was not reported as an adjunct to aneurysm surgery until $1966 .{ }^{50}$ Soon after Pool's report, ${ }^{50}$ Lougheed, Yaşargil, and others were developing microsurgical techniques to treat aneurysms. Technical advances included a number of improved aneurysm clips reported by Norlén and Olivecrona ${ }^{47}$ as well as unique microsurgical instruments. By the late 1970s, clipping of ruptured aneurysms was shown to be unequivocally superior to both bedrest and carotid artery ligation. ${ }^{25}$ Although a few centers continued to discourage any aneurysm surgery at all well into the $1970 \mathrm{~s},{ }^{30}$ most neurologists and neurosurgeons became convinced that direct clipping was the best treatment for most aneurysms.

\section{THE QUESTION OF SURGICAL TIMING}

Despite the development of this conviction by the late 1970 s, the issue of when to perform surgery was not settled. Because neurosurgeons had to convince skeptics that aneurysm clipping was practicable, a desire to optimize surgery-related results is understandable. As Norlén and Olivecrona ${ }^{47}$ had clearly shown in 1953 and many others had learned on their own, aneurysm surgery seemed to be more effective after a period of medical stabilization. Postponing surgery until the period of cerebral circulatory instability had passed seemed to lessen the risk of postoperative stroke, which was so common after early surgery. ${ }^{33}$ Ischemic problems, however, were not restricted to patients undergoing surgery. After the initial study of aneurysmal vasospasm reported by Ecker and Riemenschnei$\operatorname{der}^{17}$ in 1951, its great frequency and clinical significance began to be appreciated. Several centers noted that vasospasm was quite common and was associated with cerebral ischemia, regardless of whether surgery had been performed. In 1965, Kagstrom, et al. ${ }^{27}$ demonstrated that vasospasm was usually delayed at least 3 days after the initial subarachnoid hemorrhage. Thus, a second risk factor could be added to that of rebleeding. This had a profound effect. ${ }^{16,33}$ Those who already advocated early surgery to avoid rebleeding were joined by others who wished to avoid or ameliorate vasospasm by performing early aneurysmorrhaphy. As early as 1958, Johnson, et al. ${ }^{26}$ had recommended early removal of subarachnoid clots, in the mistaken belief that vasospasm resulted from direct pressure of the clot exerted on the arterial wall.

In the late 1960s, the cooperative study reported better outcomes when surgery was delayed until after the threat of vasospasm had passed; however, much of the difference was attributed to the higher clinical grades of patients in the late-surgery group. ${ }^{53}$ These results were echoed in the continuation of the cooperative study, published in $1974 .^{52}$ The latter study was undertaken to address some of the statistical shortcomings of the original cooperative study. As Table 2 demonstrates, surgical timing had an effect on the short-term mortality rate. The results suggested the existence of a certain amount of patient selection in the earlier study and it included too few patients to permit conclusions about ultra-early (Day 1 or 2) operation for good-grade patients. The surgery-related outcomes were clearly better after delayed surgery.

The preference for delayed surgery was maintained throughout the 1960s and 1970s by such authorities as Dott, Drake, and Yaşargil and was supported by the authors of most studies investigating overall surgery-related outcomes. The good results reported by surgeons who performed delayed surgery guaranteed the popularity of this strategy well into the 1970s and beyond. As recently as 1986, Flamm ${ }^{20}$ could make a strong case for delayed surgery. To minimize the risk of complications during the waiting period, there was a search for pharmacological agents to prevent or ameliorate vasospasm or rebleeding, some of which were used clinically. Only after their value had been disproven was there a resumption of momentum toward early operation.

At the same time, many surgeons were reluctant to deny surgery to (higher-grade) patients in better clinical condition, as this subgroup was believed to benefit from surgery. ${ }^{33}$ Norlé ${ }^{45}$ reanalyzed the early-operation results he achieved between 1949 and 1953 by examining the clinical state of the patients. He reported that over $95 \%$ of those whose preoperative state was good survived early intracranial procedures. ${ }^{45}$ Many other authorities recommended early surgery for patients with Hunt and Hess Grades I and II, and delayed surgery for those with Hunt and Hess Grade III or lower. Others relied on additional clinical factors, intracranial pressure measurements, radioisotope studies, follow-up angiography, computerized tomography-documented changes, or even cerebral blood flow measurements to optimize surgical timing.

By the 1980s the dichotomy was clear. Surgery-related outcomes could be optimized by waiting until cerebral cir-

TABLE 2

Mortality rate stratified by timing of surgery

\begin{tabular}{cccc}
\hline \hline & & \multicolumn{2}{c}{1974 Study $^{\dagger}$} \\
\cline { 3 - 4 } Timing of & $\begin{array}{c}\text { 1969 Study* } \\
\text { (741 Surgically } \\
\text { Treated Patients) }\end{array}$ & $\begin{array}{c}\text { All Surgi- } \\
\text { cally Treated } \\
\text { Patients (228) }\end{array}$ & $\begin{array}{c}\text { Good Grade } \\
\text { Patients } \\
(135)\end{array}$ \\
\hline early (1st 2 wks) & $36.7 \%$ & $44.5 \%$ & $34.0 \%$ \\
late (after 2 wks) & $17.7 \%$ & $23.2 \%$ & $18.4 \%$ \\
\hline
\end{tabular}

* Derived from Locksley.

$\dagger$ Derived from Graf and Nibbelink. 
culatory instability had passed, but this was only at the expense of management outcomes. According to Kassell and Drake, ${ }^{28}$ "[V]ast improvements have been made in operative results for ruptured aneurysm during the past three decades, but have not been reflected in a proportional improvement in overall management results." During the period of waiting prior to performing a safe operation, too many patients were experiencing rebleeding and delayed ischemia. In the mid 1970s, there was no effective medical therapy to make the waiting period safer. By this time, the mortality rate associated with clipping had decreased to the point that further microsurgical improvements could be directed toward avoiding morbidity.

New impetus for early aneurysm surgery followed timely reports by Suzuki and Yoshimoto ${ }^{59}$ and Norlén, ${ }^{43}$ whose series of early and ultra-early surgery performed in good-grade patients verified improved management mortality and morbidity rates. Aggressive prevention of hypotension and dehydration, neuroprotection with nimodipine, liberal use of ventriculostomy, postoperative endovascular treatment of vasospasm and other advances allowed many centers to improve management-related outcomes. The International Cooperative Study on the Timing of Aneurysm Surgery was able to demonstrate excellent results when performing early surgery in bettergrade patients during in the 1980s ${ }^{29}$ By the early 1990s, the benefits of early clipping had been extended even to patients with lower clinical grades.

\section{References}

1. Albright F: The syndrome produced by aneurysm at or near the junction of the internal carotid artery and the circle of Willis. Johns Hopkins Hosp Bull 44:215-245, 1929

2. Alvord EC Jr, Loeser JD, Bailey WL, et al: Subarachnoid hemorrhage due to ruptured aneurysms. A simple method of estimating prognosis. Arch Neurol 27:273-284, 1972

3. Alvord EC Jr, Thorn RB: Natural history of subarachnoid hemorrhage: early prognosis. Clin Neurosurg 24:167-175, 1977

4. Ayer WD: So-called spontaneous subarachnoid hemorrhage. A resume with its medicolegal consideration. Am J Surg 26: 143-151, 1934

5. Benson DF: Conservative vs. surgical treatment of cerebral aneurysms. Neurology 8:852-856, 1958

6. Botterell EH, Lougheed WM, Scott JW, et al: Hypothermia, and interruption of carotid, or carotid and vertebral circulation, in the surgical management of intracranial aneurysms. J Neurosurg 13:1-42, 1956

7. Dandy WE: Intracranial aneurysm of the internal carotid artery. Cured by operation. Ann Surg 107:654-659, 1938

8. Dandy WE: Intracranial arterial aneurysms. Ithaca, NY: Comstock Publishing, 1944

9. Dandy WE: Surgery of the Brain. Hagerstown, MD: Prior, 1945

10. Dandy WE: The surgical treatment of intracranial aneurysms of the internal carotid artery. Ann Surg 114:336-340, 1941

11. Davis RA: The results of delayed intracranial surgery in a series of 75 selected cerebral aneurysms. Q Bull Northwest Univ Med Sch 36:237-244, 1957

12. Denny-Brown D: The treatment of recurrent cerebrovascular symptoms and the question of "vasospasm." Med Clin North Am 35:1457-1474, 1951

13. Dott NM: Intracranial aneurysmal formations. Clin Neurosurg 16:1-16, 1969

14. Dott NM: Intracranial aneurysms: cerebral arterioradiography: surgical treatment. Edinburgh Med J 40:219-240, 1933
15. Drake CG: Earlier times in aneurysm surgery. Clin Neurosurg 32:41-50, 1985

16. Drake CG: Gordon Murray lecture. Evolution of intracranial aneurysm surgery. Can J Surg 27:549-555, 1984

17. Ecker A, Riemenschneider PA: Arteriographic demonstration of spasm of the intracranial arteries: with special reference to saccular arterial aneurysms. J Neurosurg 8:660-667, 1951

18. Falconer MA: The surgical treatment of bleeding intracranial aneurysms. J Neurol Neurosug Psychiatry 14:153-187, 1951

19. Falconer MA: Surgical treatment of spontaneous subarachnoid haemorrhage. Preliminary report. Brit Med J 1:809-813, 1950

20. Flamm ES: The timing of aneurysm surgery 1985. Clin Neurosurg 33:147-158, 1986

21. German WJ: Intracranial aneurysm: A surgical problem. Zentralbl Neurochir 3:352-354, 1938

22. Graf CJ, Nibbelink DW: Cooperative study of intracranial aneurysms and subarachnoid hemorrhage. Report on a randomized treatment study. 3. Intracranial surgery. Stroke 5: 557-601, 1974

23. Hamby WB: Intracranial Aneurysms. Springfield, IL: Charles C Thomas, 1952

24. Hunt WE, Hess RM: Surgical risk as related to time of intervention in the repair of intracranial aneurysms. J Neurosurg 28:14-20, 1968

25. Jane JA, Winn HR, Richardson AE: The natural history of intracranial aneurysms: rebleeding rates during the acute and long term period and implication for surgical management. Clin Neurosurg 24:176-184, 1977

26. Johnson RJ, Potter JM, Reid RG: Arterial spasm in subarachnoid haemorrhage: mechanical considerations. J Neurol Neurosug Psychiatry 21:68, 1958

27. Kagstrom E, Greitz T, Hanson J, et al: Changes in cerebral blood flow after subarachnoid hemorrhage, in Proceedings of the Third International Congress of Neurological Surgery, 1965. International Congress Series No. 110. Amsterdam: Excerpta Medica, 1966, pp 629-633

28. Kassell NF, Drake CG: Timing of aneurysm surgery. Neurosurgery 10:514-519, 1982

29. Kassell NF, Torner JC, Jane JA, et al: The International Cooperative Study on the Timing of Aneurysm Surgery. Part 2: surgical results. J Neurosurg 73:37-47, 1990

30. Kaste M, Troupp H: Subarachnoid haemorrhage: long-term follow-up results of late surgical versus conservative treatment. $\mathbf{B r}$ Med J 1:1310-1311, 1978

31. Keen WW: Intracranial lesions. Med News NY 57:443, 1890

32. Kurze T: Microtechniques in neurological surgery. Clin Neurosurg 11:128-137, 1964

33. Ljunggren B, Brandt L: Timing of aneurysm surgery. Clin Neurosurg 33:159-175, 1986

34. Locksley HB: Results of aneurysm treatment by intracranial surgery, carotid ligation and bed rest in defined groups of patients, in Sahs AL, Perret G, Locksley HB, et al (eds): Intracranial Aneurysms and Subarachnoid Hemorrhage. A Cooperative Study. Philadelphia: JB Lippincott, 1969, pp 245-275

35. Magladery JW: On subarachnoid bleeding - an appraisal of treatment. J Neurosurg 12:437-449, 1955

36. Magnus V: Aneurysm of the internal carotid artery. JAMA 88: 1712-1713, 1927

37. McConnell AA: Subchiasmal aneurysm treated by implantation of muscle. Zentralbl Neurochir 2:269-274, 1937

38. McKissock W, Paine K, Walsh LS: Further observations on subarachnoid haemorrhage. J Neurol Neurosurg Psychiatry 21:239-248, 1958

39. McKissock W, Paine KWE, Walsh LS: An analysis of the results of treatment of ruptured intracranial aneurysms. Report of 772 consecutive cases. J Neurosurg 17:762-776, 1960

40. McKissock W, Richardson A, Walsh L: Posterior-communicating aneurysms. A controlled trial of the conservative and surgi- 
cal treatment of ruptured aneurysms of the internal carotid at or near the point of origin of the posterior communicating artery. Lancet 1:1203-1206, 1960

41. Merritt HH: A Textbook of Neurology, ed 3. Philadelphia: Lea \& Febiger, 1963

42. Nishioka H: Results of the treatment of intracranial aneurysms by occlusion of the carotid artery in the neck. J Neurosurg 25: 660-704, 1966

43. Norlén G: Experiences with intracranial aneurysm surgery: results in early operations, in XVI Congreso Latino-Americano de Neurocirurgia. Caracas, Venezuela, 1975, pp 235-245

44. Norlén G: The pathology, diagnosis and treatment of intracranial saccular aneurysms. Proc Royal Soc Med 45:291-302, 1952

45. Norlén G: Some aspects of the surgical treatment of intracranial aneurysms. Clin Neurosurg 9:214-222, 1963

46. Norlén G, Barnum AS: Surgical treatment of aneurysms of the anterior communicating artery. J Neurosurg 10:634-650, 1953

47. Norlén $\mathrm{G}$, Olivecrona $\mathrm{H}$ : The treatment of aneurysms of the circle of Willis. J Neurosurg 10:404-415, 1953

48. Pakarinen S: Incidence, aetiology, and prognosis of primary subarachnoid haemorrhage. A study based on 589 cases diagnosed in a defined urban population during a defined period. Acta Neurol Scand 43 (Suppl 29):1-28, 1967

49. Pool JL: The development of modern intracranial aneurysm surgery. Neurosurgery 1:233-237, 1977

50. Pool JL, Colton RP: The dissecting microscope for intracranial vascular surgery. J Neurosurg 25:315-318, 1966

51. Roberts JG: Surgery of intracranial aneurysms. Br Med J 1: 1107, 1956

52. Sahs AL: Cooperative study of intracranial aneurysms and subarachnoid hemorrhage. Report on a randomized treatment study. I. Introduction. Stroke 5:550-551, 1974

53. Sahs AL, Perret G, Locksley HB, et al (eds): Intracranial Aneurysms and Subarachnoid Hemorrhage: A Cooperative Study. Philadelphia: Lippincott, 1969

54. Schorstein J: Carotid ligation in saccular intracranial aneurysms. Br J Surg 28:50-70, 1940
55. Sjöquist O: Thread ligature of intracranial saccular aneurysms, in 5th Congress of Neurology. Lisbon, Portugal, 1953, Vol 3, pp 108-115

56. Slosberg P: Treatment and prevention of stroke. I. Subarachnoid hemorrhage due to ruptured intracranial aneurysm. NY State J Med 73:679-688, 1973

57. Sossman MC, Vogt EC: Aneurysms of the internal carotid artery and the circle of Willis, from a roentgenological viewpoint. AJR 15:122-134, 1926

58. Sundt TM: Surgical Techniques for Saccular and Giant Intracranial Aneurysms. Baltimore, MD: Williams \& Wilkins, 1990, pp xv-xxiii

59. Suzuki J, Yoshimoto T: Early operation for the ruptured intracranial aneurysm. Jpn J Surg 3:149-156, 1973

60. Tappura M: Prognosis of subarachnoid haemorrhage. A study of 120 patients with unoperated intracranial aneurysms and 267 patients without vascular lesions demonstrable in bilateral carotid angiograms. Acta Med Scand Suppl 392:1-75, 1962

61. Tönnis W: Traumatischer Aneurysma der linken Art. carotis int mit Embolie der linken Art. cerebri ant. und retinae. Zentrabl f Chir 61:844-848, 1934

62. Winn HR, Richardson A, Jane JA: Proceedings: Late mortality and morbidity of common carotid ligation for posterior communicating artery aneurysms: a comparison with conservative treatment. J Neurol Neurosurg Psychiatry 38:406, 1975

63. Winn HR, Richardson AE, Jane JA: The long-term prognosis in untreated cerebral aneurysms: I. The incidence of late hemorrhage in cerebral aneurysm: a 10-year evaluation of 364 patients. Ann Neurol 1:358-370, 1977

Manuscript received May 17, 2001.

Accepted in final form July 11, 2001.

Address reprint requests to: Sherman C. Stein, M.D., Department of Neurosurgery, Hospital of the University of Pennsylvania, Fifth Floor Silverstein Building, University of Pennsylvania Medical Center, 3400 Spruce Street, Philadelphia, Pennsylvania 19104. email: mssstein@voicenet.com. 